\title{
CA125-Tn ELISA assay improves specificity of pre-operative diagnosis of ovarian cancer among patients with elevated serum CA125 levels
}

\author{
Yi-Sheng Wang ${ }^{1}$, Shi-Fang Ren ${ }^{2,3}$, Wei Jiang ${ }^{1}$, Jia-Qi Lu ${ }^{1}$, Xiao-Yan Zhang ${ }^{1}$, Xiao-Ping Li ${ }^{4}$, Rui Cao ${ }^{5}$, \\ Cong-Jian $\mathrm{Xu}^{1,6,7,8}$
}

${ }^{1}$ Obstetrics and Gynecology Hospital of Fudan University, Shanghai, China; ${ }^{2}$ Key Laboratory of Glycoconjugate Research Ministry of Public Health, Shanghai, China; ${ }^{3}$ Department of Biochemistry and Molecular Biology, School of Basic Medical Sciences, Fudan University, Shanghai, China; ${ }^{4}$ Peking University People's Hospital, Beijing, China; ${ }^{5}$ Dalian Obstetrics \& Gynecology Hospital, Liaoning, China; ${ }^{6}$ Department of Obstetrics and Gynecology of Shanghai Medical School, Fudan University, Shanghai, China; ${ }^{7}$ Institute of Biomedical Sciences, Fudan University, Shanghai, China; ${ }^{8}$ Shanghai Key Laboratory of Female Reproductive Endocrine Related Diseases, Shanghai, China

Contributions: (I) Conception and design: YS Wang, SF Ren, W Jiang, CJ Xu; (II) Administrative support: YS Wang, XY Zhang, CJ Xu; (III) Provision of study materials or patients: W Jiang, JQ Lu, XP Li, R Cao; (IV) Collection and assembly of data: YS Wang, W Jiang, JQ Lu, XP Li, XY Zhang, R Cao; (V) Data analysis and interpretation: YS Wang, SF Ren, CJ Xu; (VI) Manuscript writing: All authors; (VII) Final approval of manuscript: All authors.

Correspondence to: Congjian Xu, MD, PhD. 419, Fangxie Road, Shanghai 200011, China. Email: xucj@hotmail.com; Shi-Fang Ren, PhD. 130, Dongan Road, Shanghai 200032, China. Email: renshifang@fudan.edu.cn.

Background: CA125 is the most widely used serum marker for preoperative diagnosis of ovarian cancer. However, CA125 elevation is not specific to ovarian cancer. More than $60 \%$ of patients who have elevated CA125 levels do not have ovarian cancer. To overcome the low specificity of CA125, we identified a CA125 glycoform that was specifically elevated in ovarian cancer and that may help in the further triage of patients with elevated serum CA125 levels.

Methods: We used antibody-lectin ELISA to detect various CA125 glycoforms. Among 21 lectins tested, VVA, a plant lectin that preferentially binds Tn antigen, showed significantly stronger binding with ovarian cancer-derived CA125 than benign condition-derived CA125. CA125-Tn levels were tested among patients with elevated CA125 levels ( $\mathrm{n}=328$, including 68 ovarian cancer, 15 ovarian borderline tumors, and 245 benign conditions). The efficacy of CA125-Tn in diagnosing ovarian cancer was evaluated using ROC analysis.

Results: Medians and $25^{\text {th }}$ to $75^{\text {th }}$ quartiles of CA125-Tn levels were $0.31(0.18-0.65)$ in ovarian cancer, 0.07 $(0.02-0.12)$ in ovarian borderline tumor, and $0.07(0.01-0.12)$ in benign conditions. AUC of the ROC curve was 0.890 (95\% CI: $0.845,0.935$ ) for CA125-Tn to discriminate ovarian cancer cases from nonmalignant cases (borderline tumors and benign conditions). Its performance was even better among patients older than 45 y (AUC: $0.905,95 \%$ CI: 0.841, 0.969). Specificity was improved from $35.1 \%$ for CA125 to $75.7 \%$ for CA125-Tn among patients older than $45 \mathrm{y}$ when sensitivity was fixed at $90 \%$.

Conclusions: CA125-Tn ELISA assay can improve specificity of the preoperative diagnosis of ovarian cancer and serve as a further triage strategy for patients with elevated CA125 levels.

Keywords: Ovarian cancer; CA125; glycoforms; Tn antigen; diagnosis

Submitted Dec 18, 2020. Accepted for publication Feb 26, 2021.

doi: $10.21037 /$ atm-20-8053

View this article at: http://dx.doi.org/10.21037/atm-20-8053 


\section{Introduction}

Ovarian cancer remains the leading cause of death from gynecological malignancies. Symptoms of ovarian cancer are nonspecific. Most patients are diagnosed only when the disease has progressed to an advanced stage (1). Optimal cytoreduction, which requires a well-trained gynecological oncologist, is a key factor for improved survival (2). The quality of first surgery is a strong prognostic indicator. However, due to the large prevalence of ovarian cysts or masses, it is not feasible for all patients with ovarian cysts, whether benign or malignant, to be managed by gynecological oncologists. Patients need to be triaged preoperatively $(3,4)$.

Preoperative diagnosis of ovarian cancer relies mainly on serum CA125 levels and imaging tests such as computed tomography scan and ultrasonography. However, neither sensitivity, nor specificity is satisfactory (5). Elevations in the serum CA125 concentration have been observed in most non-mucinous epithelial ovarian cancer patients (6). The sensitivity for CA125 to detect ovarian cancer is approximately $80 \%$ (7). However, patients with benign gynecological diseases such as endometriosis (8) and pelvic inflammatory disease (9), or even apparently healthy women (10) may also have elevated serum CA125 levels (11). It has been reported that endometriosis, which affects more than $10 \%$ of women of reproductive age and commonly presents with an adnexal mass, causes increased CA125 levels in up to $67 \%$ of patients (12). Previous single center hospital study showed that of 191 patients with abnormal CA125 levels, only 39 (20\%) patients were demonstrated to have ovarian cancer by pathological examination (13). Fortyeight (26\%) had nonovarian/gynecological malignancies. As many as $54 \%$ of the patients had benign diseases or normal results after thorough examination. According to results from the Prostate, Lung, Colorectal and Ovarian (PLCO) screening trial (the largest clinical trial to date assessing the efficacy of ovarian cancer screening in general population), positive predictive value for CA125 alone is only $3.7 \%$ (14). Above all, a more accurate preoperative triage strategy for ovarian cancer is urgently needed.

CA125 is a highly glycosylated mucin encoded by the MUC16 gene (15). In healthy women, it is synthesized mainly by mesothelial cells and inner layer of female genital tract $(16,17)$. Irritations to mesothelium, such as ascites and pelvic inflammatory disease, are common causes of elevated serum CA125 levels $(18,19)$. In contrast, ovarian cancer cells synthesize and secrete CA125 in large amounts. The serum level of CA125 in ovarian cancer patients is positively correlated with cancer tissue staining $(20,21)$, suggesting that cancerous tissue is the main source of serum CA125 in those patients. It is well known that obvious changes occur in glycosylation machinery in malignant tissues, which result in aberrant glycan patterns on glycoproteins synthesized by these cancerous tissues (22-24). Thus, it is reasonable to expect a distinct glycosylation pattern on ovarian cancer-derived CA125 molecules as compared with benign CA125 molecules. Previous studies reported increased glycans, such as truncated O-glycans and sialyl Tn antigen (STn), in ovarian cancer-associated CA125 (25-27). These may serve as biomarkers to help in the differential diagnosis of patients with elevated CA125 levels.

In searching for this, we established an antibody-lectin ELISA assay for detection of glycans attached to CA125 molecules. Of 21 lectins tested, VVA [Vicia Villosa Lectin, preferentially binds Tn antigen (alpha-GalNAc-O-Ser/ Thr)] showed the best differentiation efficacy when used as the detecting lectin. Performance of this antibody-lectin ELISA assay (termed the CA125-Tn ELSA assay) was demonstrated to be satisfactory for preoperative triage of patients suspected of having ovarian cancer (with a positive CA125 test result). We present the following article in accordance with the STARD reporting checklist (available at http://dx.doi.org/10.21037/atm-20-8053).

\section{Methods}

\section{Patients}

Patient recruitment was conducted at multiple sites, including Obstetrics \& Gynecology Hospital of Fudan University, Peking University People's Hospital, Cancer Center of Shanxi Province, Dalian Obstetrics \& Gynecology Hospital, Huai'an First People's Hospital, and Central Hospital of Fengxian District, from September 2011 to April 2018. Patients who met the following criteria were included in this study: (I) elevated serum CA125 $(\geq 35 \mathrm{U} / \mathrm{mL}$ ) before treatment; (II) confirmed diagnosis by histopathological examination for whom surgery was performed, or by clinical examination and investigations for those surgery was not required for diagnosis; and (III) more than $300 \mu \mathrm{L}$ of serum sample remaining after CA125 testing. Pregnant patients were excluded from this study. Leftover serum samples after CA125 testing were collected and stored at $-80{ }^{\circ} \mathrm{C}$ before use. Data concerning each patient's age, menopausal status, imaging findings, diagnosis, histological type, stage, and grade were collected (Table 1). This study was conducted in accordance with the 
Table 1 Patient characteristics

\begin{tabular}{|c|c|c|c|c|c|c|}
\hline & $\mathrm{N}$ & $\begin{array}{c}\text { Age }(y) \\
\text { mean } \pm S D\end{array}$ & $\begin{array}{l}\text { Post-menopause, } \\
\text { N (\%) }\end{array}$ & $\begin{array}{c}\mathrm{CA} 125(\mathrm{U} / \mathrm{mL}) \\
\text { mean } \pm \mathrm{SD}\end{array}$ & $\begin{array}{l}\text { CA125-Tn, } \\
\text { mean } \pm S D\end{array}$ & $\mathrm{P}$ \\
\hline Ovarian cancer & 68 & $53 \pm 11$ & $35(50.7)$ & $679.06 \pm 993.33$ & $0.44 \pm 0.33$ & Reference \\
\hline Serous & 56 & $55 \pm 10$ & $32(57.1)$ & $757.60 \pm 1,066.23$ & $0.49 \pm 0.33$ & \\
\hline Mucinous & 6 & $44 \pm 15$ & $2(33.3)$ & $114.90 \pm 55.46$ & $0.07 \pm 0.03$ & \\
\hline Ovarian borderline tumor & 15 & $32 \pm 8$ & $1(6.7)$ & $288.26 \pm 185.56$ & $0.10 \pm 0.13$ & $<0.001$ \\
\hline Serous & 13 & $33 \pm 9$ & $1(7.7)$ & $276.08 \pm 173.07$ & $0.08 \pm 0.10$ & \\
\hline Mucinous & 2 & $28 \pm 3$ & $0(0.0)$ & $367.40 \pm 328.94$ & $0.23 \pm 0.26$ & \\
\hline PID & 31 & $36 \pm 10$ & $1(3.2)$ & $315.16 \pm 271.71$ & $0.15 \pm 0.16$ & \\
\hline Teratoma & 4 & $38 \pm 13$ & $0(0.0)$ & $150.77 \pm 37.52$ & $0.03 \pm 0.06$ & \\
\hline Tuberculosis & 3 & $25 \pm 5$ & $0(0.0)$ & $420.45 \pm 284.61$ & $0.16 \pm 0.12$ & \\
\hline Ovarian adenoma & 2 & $52 \pm 40$ & $1(50.0)$ & $235.55 \pm 86.06$ & $0.06 \pm 0.06$ & \\
\hline Others & 18 & $38 \pm 14$ & $1(5.5)$ & $214.20 \pm 220.17$ & $0.10 \pm 0.08$ & \\
\hline
\end{tabular}

PID, pelvic inflammatory disease; P: comparisons of CA125-Tn level means to patients with ovarian cancer.

Declaration of Helsinki (as revised in 2013). This study was approved by the Institutional Review Board of Obstetrics \& Gynecology Hospital of Fudan University (2017-52). In this study, we used only serum samples left over after clinical testing. No additional serum sample was collected outside the standard clinical requirement. Thus, written informed consent from participants was not required and was waived by the Institutional Review Board.

\section{Microplate fabrication and preparation}

Antibodies are glycoproteins. Glycans attached to the Fc fragment will bind lectins and thus interfere with the detection of glycans on antigens in the antibody-lectin assay. To eliminate interference from antibody glycans, we performed derivatization of the anti-CA125 antibody after coating. The procedure was performed as described by Chen et al. in 2007 with modifications (Figure 1) (28). First, a 96-well microplate was coated with $1 \mu \mathrm{g} / \mathrm{mL}$ antiMUC16 antibody (Abcam, USA, clone X325) in $\mathrm{Na}_{2} \mathrm{CO}_{3}-$ $\mathrm{NaHCO}_{3}$ buffer $(0.05 \mathrm{M}, \mathrm{pH} 9.6)$ overnight at $4{ }^{\circ} \mathrm{C}$. After washing with PBST0.1 three times to remove unbound antibody, the plate was incubated in a blocking solution of PBST0.1 containing $1 \%$ BSA at $37{ }^{\circ} \mathrm{C}$ for 1 hour. Then, $20 \mathrm{mM} \mathrm{NaIO} 4$ in coupling buffer $(0.1 \mathrm{M}$ sodium acetate, $\mathrm{pH} 5.5$ ) was added to oxidize the sugar groups on the antibody, and the plate was incubated in the dark at $4{ }^{\circ} \mathrm{C}$ for 2.5 hours. After a brief rinse, the plate was incubated with $1 \mathrm{mM}$ 4-(4-N-maleimidophenyl)butyric acid hydrazide hydrochloride (MPBH; Pierce Biotechnology) for 2 hours at room temperature to derivatize the carbonyl groups. Finally, $1 \mathrm{mM}$ Cys-Gly dipeptide (Sigma Aldrich, USA) in PBST0.1 was reacted with maleimide on $\mathrm{MPBH}$, and sugar groups were blocked overnight at $4{ }^{\circ} \mathrm{C}$.

\section{Antibody-lectin assay}

Microplates coated with derivatized anti-CA125 (X325) were used for the antibody-lectin assay. Briefly, $100 \mu \mathrm{L}$ of serum ( $100 \mu \mathrm{L}$ of PBS as blank) was added to the plate and incubated at $37^{\circ} \mathrm{C}$ for $90 \mathrm{~min}$. The plate was washed 3 times with PBST0.1 to remove unbound proteins and then incubated with $10 \mu \mathrm{g} / \mathrm{mL}$ of biotin-lectins (Vector, USA) at room temperature for 1 hour. After 6 washes with PBST0.1, 

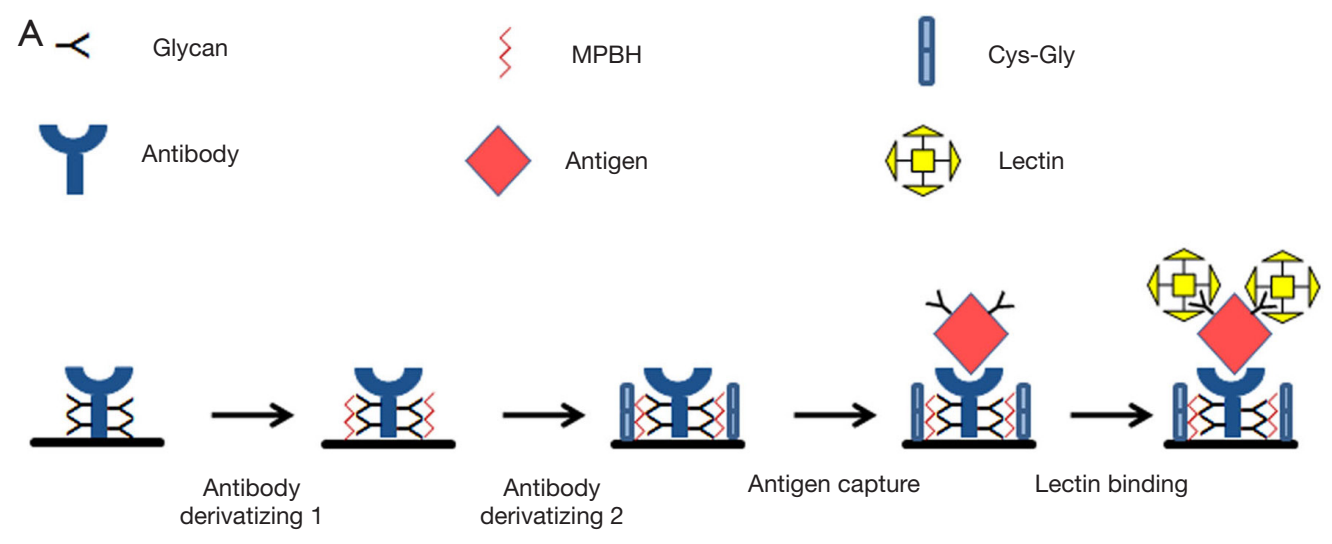

B

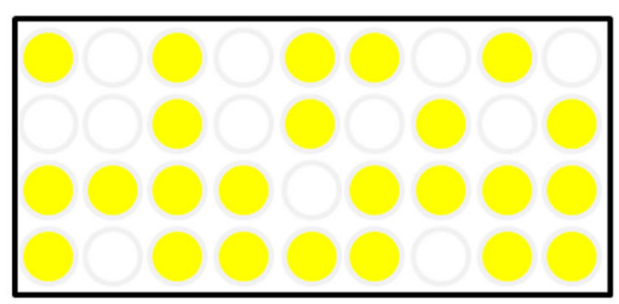

Malignant cases

Benign cases

Figure 1 Derivatizing of glycans on IgG Fc fragments. (A) Experimental scheme; (B) Example of results of the antibody-lectin ELISA assay.

streptavidin-HRP (Vector, USA) was added to bind with biotin-lectins. After another 6 washes, color development was performed using TMB solution (Excel, China) in the dark for $10 \mathrm{~min}$ and stopped by $1 \mathrm{~N}$ HCL. The optical density (OD) of each well was estimated at $\mathrm{A}_{405}$ using a microplate reader (Perkin Elmer, USA). Each sample was tested in duplicate, and the results were averaged.

\section{Statistical analysis}

The CA125-Tn value for serum samples was calculated as the logarithm of $\mathrm{A}_{405}$ in sample cells minus the value from blank cells. CA125-Tn levels in ovarian cancer, ovarian borderline tumor, and benign conditions were compared using Student's $t$ test. Comparisons of CA125-Tn levels between different histological types, stages, and grades were performed using one-way analysis of variance (ANOVA). Diagnostic performance of the CA125-Tn ELISA assay was evaluated with receiver operating characteristic (ROC) curves analysis. All statistical analyses were performed using PASW Statistics software, version 17.0.

\section{Results}

\section{Selection of lectins for antibody-lectin assay}

Twenty-one lectins (see Table S1) were screened for the detection of CA125 glycoforms using an antibody-lectin assay. To reduce background signals caused by lectin binding with antibody glycans, we first performed chemical derivatization of the coating antibody before antigen capture. As shown in Figure 2A, strong binding of AAL, ConA, LCA, ACL, MALII, PSA, and SNA with the coating antibody was observed. After derivatization, background signals in LCA, PSA, and SNA were significantly reduced. However, moderate reductions in ConA and MAL-II and no reductions in AAL and ACL were observed. Thus, LCA, PSA, and SNA, together with DBA, ECL, E-PHA, L-PHA, MAL-I, PNA, RCA, UEA, VVA, BPL, DSL, EEL, GNL, LTL, and SBA, which showed weak binding with the coating antibody, had background signals low enough for the antibody-lectin assay. After incubation of serum with the derivatized antibody, lectin binding signals were enhanced, indicating that the antibody retained its capacity for CA125 binding after derivatization.

To confirm that lectins bind with CA125 through specific glycan recognition, we preincubated lectins with their corresponding inhibiting monosaccharides before they were used in the antibody-lectin assay. Binding of DBA, ECL, MAL-I, RCA, VVA, BPL, EEL, LTL, PSA, SBA, or UEA with CA125 were significantly inhibited by monosaccharide in a concentration-dependent manner (Figure $2 B$ and Table S1).

Then, we sought to find whether lectins bind specifically with glycans carried by CA125 molecules but not by 

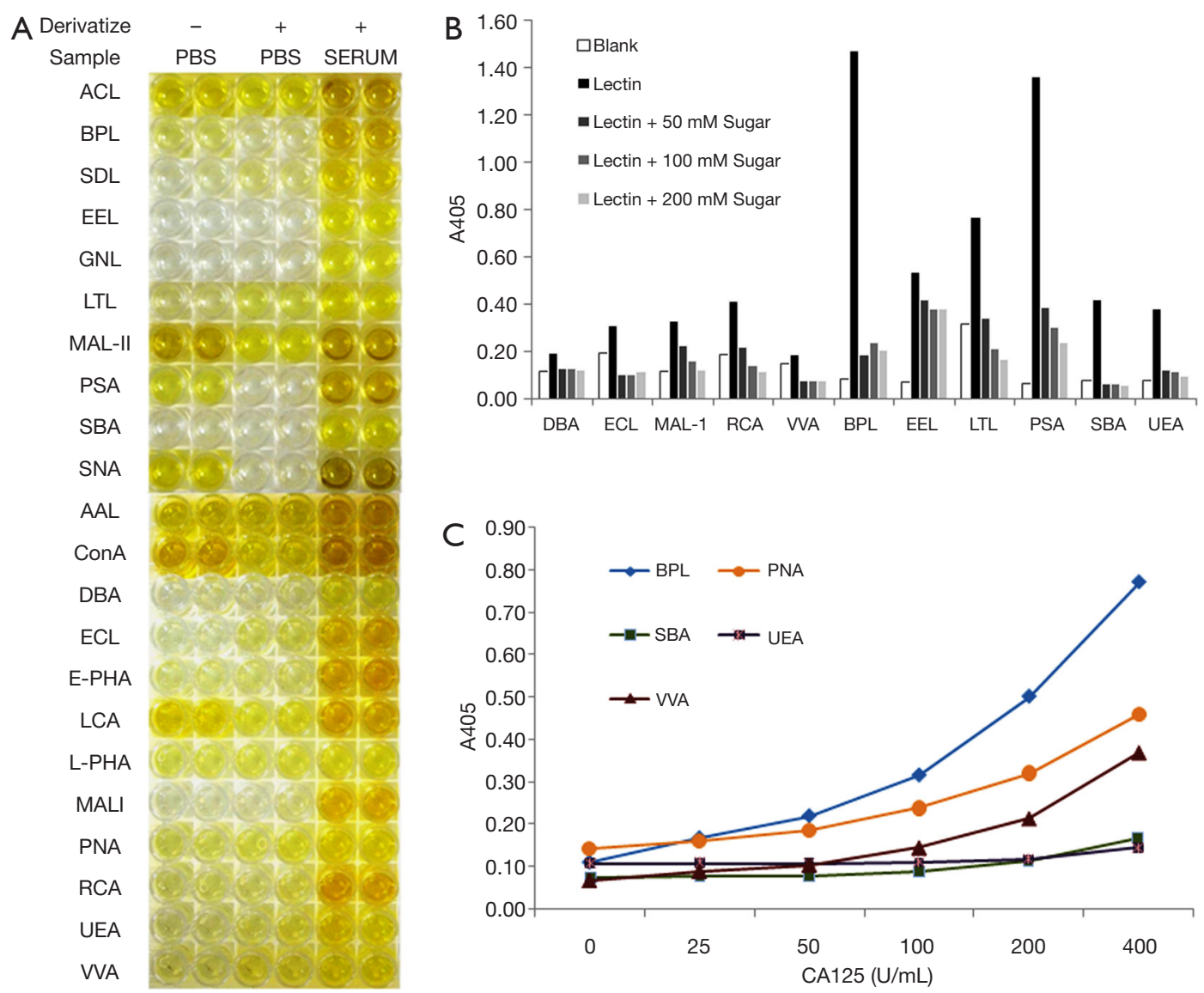

Figure 2 Microplate fabrication. (A) Derivatizing glycans attached to the Fc fragment of the antibody significantly reduced the background signal in the antibody-lectin ELISA assay; (B) Lectin binding with antigens was inhibited by its corresponding inhibiting sugars; (C) Lectin binding had a linear relationship with the concentration of CA125.

antibodies or other nonspecific serum proteins. To investigate this, we assessed the linear relationship between CA125 concentration and signal intensity of lectins. CA125 was first immunodepleted from serum, and then purified CA125 was incorporated at varying concentrations. Signal intensities of BPL, PNA, SBA, UEA, and VVA showed a positive correlation with the concentration of CA125 (Figure 2C).

\section{VAA binds preferentially with ovarian cancer-derived CA125}

Generally, CA125 levels in patients with ovarian cancer are higher than those in patients with benign diseases. Thus, glycans that are overexpressed in ovarian cancerderived CA125 may enlarge the gap and therefore help in the differential diagnosis of patients with elevated CA125 levels. We chose 7 benign gynecological disease patients with CA125 higher than $100 \mathrm{U} / \mathrm{mL}$ and 7 ovarian cancer patients with CA125 lower than $200 \mathrm{U} / \mathrm{mL}$ to examine the differential efficacies of these five lectins in the antibody-lectin assay. Among them, VVA displayed the most significant difference in signal intensity between the two groups (Figure S1). VVA is a lectin that specifically recognizes Tn antigen (29). Therefore, an antibody-lectin assay using VVA as the detecting lectin (termed the as CA125-Tn ELISA) was further tested for its differential efficacy in a larger population. The intra- and interassay variation for CA125Tn ELISA were estimated to range from $8 \%$ to $10 \%$.

\section{CA125-Tn level was higher in ovarian cancer patients}

We enrolled 328 patients with serum CA125 levels equal to or greater than $35 \mathrm{U} / \mathrm{ml}$, including 68 ovarian cancers, 15 ovarian borderline tumors, and 245 benign conditions (Table 1). Endometriosis, adenomyosis, and pelvic 


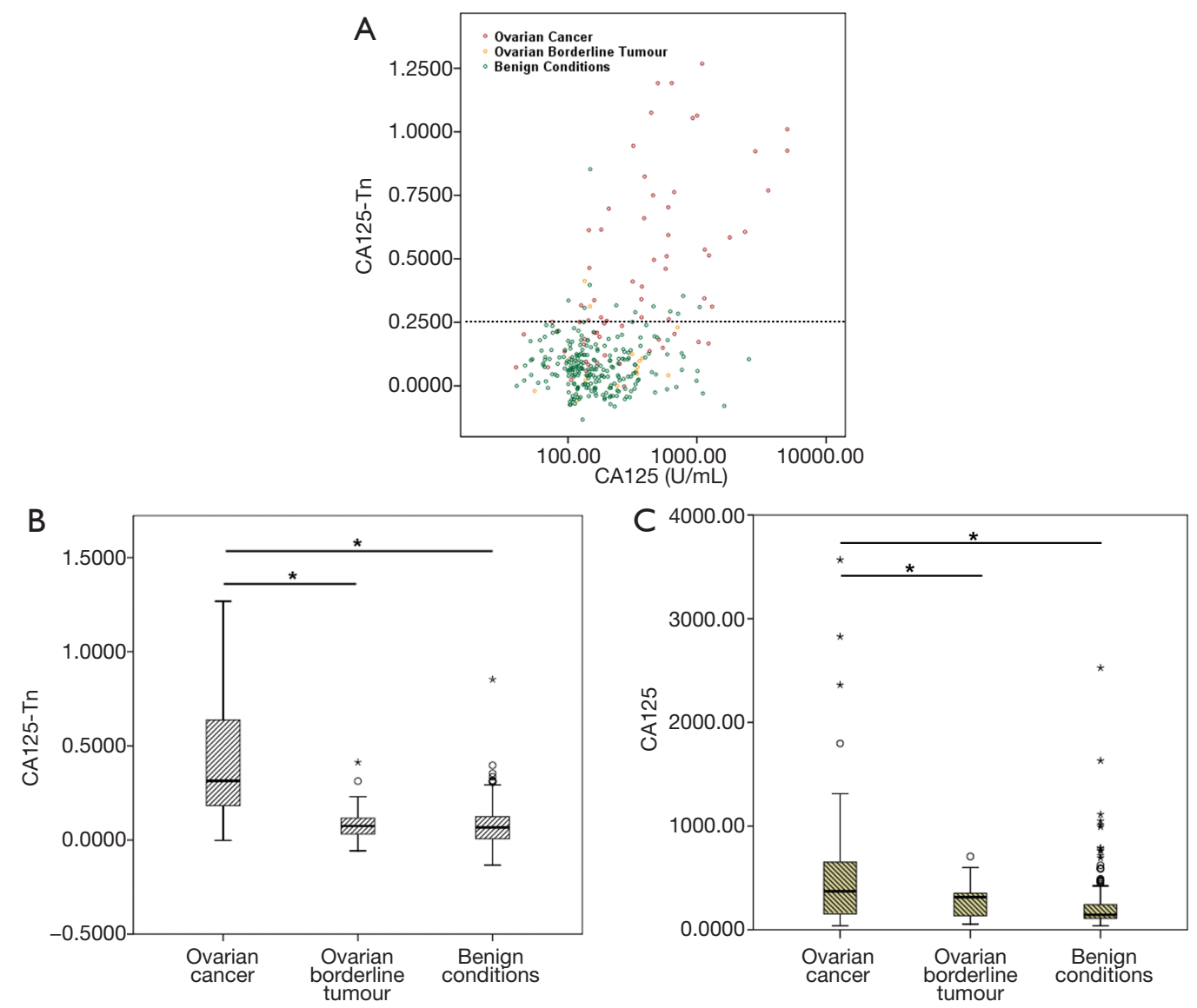

Figure 3 CA125-Tn and CA125 levels in ovarian cancer, ovarian borderline tumor, and benign conditions. (A) Most ovarian cancer patients have CA125-Tn levels above 0.25; ovarian cancer patients have higher CA125-Tn (B) and CA125 (C) levels than patients with borderline ovarian tumor or benign gynecological conditions. *, $\mathrm{P}<0.05$.

inflammatory disease comprised $89 \%$ of the benign condition group. CA125-Tn levels were significantly higher in patients with ovarian cancer than in those with ovarian borderline tumor or benign conditions (Figure 3). No significant difference between the benign and borderline groups was observed. Medians, $25^{\text {th }}$ and $75^{\text {th }}$ quartiles of CA125-Tn levels were $0.31(0.18-0.65)$ for ovarian cancer, $0.07(0.02-0.12)$ for ovarian borderline tumor, and 0.07 (0.01-0.12) for benign conditions. Among the different histotypes, serous $(\mathrm{n}=56)$ and clear cell ovarian cancer $(\mathrm{n}=6)$ showed higher CA125-Tn levels than mucinous $(n=3)$ or endometrioid ( $\mathrm{n}=3$ ) ovarian cancer (Table 1).

\section{CA125-Tn ELISA improves ovarian cancer diagnosis among patients with elevated CA125 levels}

For patients with positive CA125, receiver operating characteristic (ROC) curves analysis showed that the area under the curve (AUC) for CA125-Tn and CA125 to discriminate ovarian cancer patients from nonmalignant patients (both borderline tumors and benign conditions) was 0.890 (95\% CI: $0.845,0.935)$ and 0.721 (95\% CI: 0.648, 0.795), respectively (Figure 4A). Sensitivity for CA125-Tn to detect ovarian cancer was $72.1 \%$, with a fixed specificity of $90 \%$. However, it was only $44.1 \%$ for CA125. When sensitivity was fixed at $90 \%$, specificity was improved from $20.1 \%$ for CA125 to $58.3 \%$ for CA125-Tn.

Patients with ovarian cancer were generally older than patients with borderline tumors or benign conditions in our cohort (Table 1). To avoid the effects of age bias on CA125 and CA125-Tn levels, we analyzed performance in two age subsets $(>45 \mathrm{y}$ and $\leq 45 \mathrm{y})$. For patients older than $45 \mathrm{y}$, AUCs of the ROC curves for CA125-Tn and CA125 to discriminate ovarian cancer patients from nonmalignant 

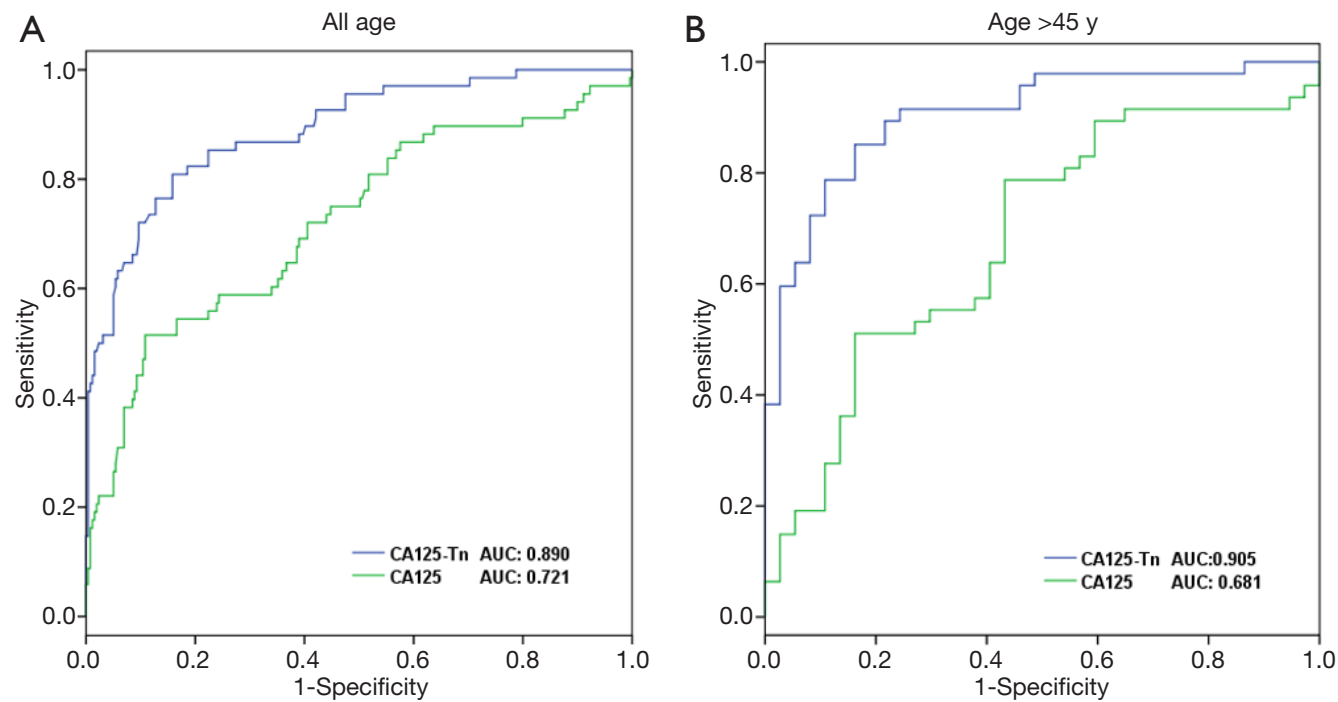

Figure 4 ROC curve of CA125-Tn and CA125 to detect ovarian cancer among patients with elevated CA125 levels. (A) Cases of all age, (B) Cases older than $45 \mathrm{y}$.

patients (both borderline tumors and benign conditions) were 0.905 (95\% CI: $0.841,0.969)$ and 0.681 (95\% CI: $0.565,0.798$ ), respectively (Figure $4 B$ ). At a fixed sensitivity of $90 \%$, specificity was improved from $35.1 \%$ for CA125 to $75.7 \%$ for CA125-Tn. Due to the low case number of ovarian cancer patients, ROC analysis could not be performed among patients aged $45 \mathrm{y}$ or younger (data not shown).

\section{Discussion}

Despite many promising new markers, CA125 remains the single-best biomarker for ovarian cancer (30). A significant drawback of CA125 is its low specificity. To address this problem, various combinations of ovarian cancer biomarkers were tested. However, none of them provided significant improvement in diagnostic accuracy $(31,32)$. In this study, we specifically focused on patients with elevated serum CA125 levels, aiming to find a CA125 glycoform that is elevated in patients with ovarian cancer, which will help in the preoperative triage of patients with abnormal CA125 levels. We employed an antibody-lectin ELISA assay to detect various CA125 glycoforms. Among 21 lectins, VVA, a plant lectin that specifically binds Tn antigen, was demonstrated to be the most powerful in differentiating patients with ovarian cancer from those with benign conditions or ovarian borderline tumors. For patients older than $45 \mathrm{y}$, CA125-Tn performed even better in improving specificity. This novel assay will be useful for the differential diagnosis of patients with positive CA125 levels. However, it has no effects in discriminating borderline ovarian tumors from benign gynecological patients.

Tn antigen is an O-glycan structure demonstrated to be upregulated in many malignant tissues $(33,34)$. In ovarian cancer, upregulation of Tn antigen was also manifested in cancerous tissues (35). Additionally, CA125, the predominant mucin secreted by ovarian cancer was reported to carry Tn antigen in large amounts $(25,36)$. Unsurprisingly, CA125-Tn, which combined both CA125 level and Tn level, improved the diagnosis of ovarian cancer. This was also demonstrated by Salminen et al., who found that CA125-Tn (detected with macrophage galactose-type lectin) was helpful in differential diagnosis of pelvic masses (37).

CA125 is a highly glycosylated, huge mucin with a molecular weight of 200 to $4,000 \mathrm{KD}$. Glycans account for up to $70 \%$ of its molecular weight (15). CA125 molecules are highly heterogeneous in terms of both molecular weight and glycan modification, which makes structural investigation difficult (38-40). Variations in glycoforms on CA125 molecules from different sources have long been recognized. In 2008, Jankovic et al. analyzed the lectin binding profile of CA125 purified from an ovarian cancer cell line and amniotic fluid (36). They demonstrated increased RCA-, WFA-, PHA-E-, PHA-L-, SBA-, and MAA-binding fractions and decreased WGA- and UEA-binding fractions in CA125 purified from ovarian cancer cell line, indicating 
increased bisecting $\mathrm{N}$-glycan, multiantennary $\mathrm{N}$-glycan and Tn antigen modification on ovarian cancer-derived CA125 molecules. In contrast to CA125 purified from the placenta, in which only core fucose was detected, Wong et al. showed both core and outer fucose on ovarian cancerderived CA125 $(39,41)$. Most of these investigations employed chromatography or mass spectrometry or both for CA125 glycoform profiling, which requires a large amount of purified CA125. However, these time- and material-consuming methods are not appropriate for routine clinical sample testing. Therefore, we turned to an antibody-lectin ELSA assay, in which only $200 \mu \mathrm{L}$ of serum sample was required for glycosylation pattern analysis of CA125. The major disadvantage of this method is its high background signal caused by glycans on coating antibodies or nonspecifically binding proteins, which increases the lower limit of the test $(42,43)$. In this study, we used a glycan derivatizing strategy developed by Chen et al. (28) to reduce signals from antibody glycans, which made the detection of CA125-Tn in low abundance possible.

\section{Conclusions}

In this study, we developed a novel immunoassay, the CA125-Tn assay, for detecting ovarian cancer among patients with positive CA125 results. It improved specificity while maintaining satisfactory sensitivity. This assay warrants further validation in a larger population.

\section{Acknowledgments}

Language of this manuscript was edited by American Journal Experts.

Funding: This work was supported by grants from the National Key R\&D Program of China (2016YFC1303101) and Shanghai Science and Technology Development Program (15DZ1941002).

\section{Footnote}

Reporting Checklist: The authors have completed the STARD reporting checklist. Available at http://dx.doi.org/10.21037/ atm-20-8053

Data Sharing Statement: Available at http://dx.doi. org/10.21037/atm-20-8053

Peer Review File: Available at http://dx.doi.org/10.21037/ atm-20-8053

Conflicts of Interest: All authors have completed the ICMJE uniform disclosure form (available at http://dx.doi. org/10.21037/atm-20-8053). Dr. YSW, Dr. JQL, Dr. XYZ, Dr. XPL, Dr. RC, and Dr. CJX report that they have a patent CA125-Tn ELISA kit licensed to Obstetrics and Gynecology Hospital of Fudan University. The other authors have no conflicts of interest to declare.

Ethical Statement: The authors are accountable for all aspects of the work in ensuring that questions related to the accuracy or integrity of any part of the work are appropriately investigated and resolved. The study was conducted in accordance with the Declaration of Helsinki (as revised in 2013). This study was approved by the Institutional Review Board of Obstetrics \& Gynecology Hospital of Fudan University (2017-52). In this study, we used only serum samples left over after clinical testing. No additional serum sample was collected outside the standard clinical requirement. Thus, written informed consent from participants was not required and was waived by the Institutional Review Board.

Open Access Statement: This is an Open Access article distributed in accordance with the Creative Commons Attribution-NonCommercial-NoDerivs 4.0 International License (CC BY-NC-ND 4.0), which permits the noncommercial replication and distribution of the article with the strict proviso that no changes or edits are made and the original work is properly cited (including links to both the formal publication through the relevant DOI and the license). See: https://creativecommons.org/licenses/by-nc-nd/4.0/.

\section{References}

1. Webb PM, Jordan SJ. Epidemiology of epithelial ovarian cancer. Best Pract Res Clin Obstet Gynaecol 2017;41:3-14.

2. Eskander RN, Kauderer J, Tewari KS, et al. Correlation between Surgeon's assessment and radiographic evaluation of residual disease in women with advanced stage ovarian cancer reported to have undergone optimal surgical cytoreduction: An NRG Oncology/Gynecologic Oncology Group study. Gynecol Oncol 2018;149:525-30.

3. Guidelines for referral to a gynecologic oncologist: rationale and benefits. The Society of Gynecologic Oncologists. Gynecol Oncol 2000;78:S1-13.

4. ACOG Committee Opinion: number 280, December 
2002. The role of the generalist obstetrician-gynecologist in the early detection of ovarian cancer. Obstet Gynecol 2002;100:1413-6.

5. van Nagell JR, Jr., Hoff JT. Transvaginal ultrasonography in ovarian cancer screening: current perspectives. Int J Womens Health 2013;6:25-33.

6. Hogdall EV, Christensen L, Kjaer SK, et al. CA125 expression pattern, prognosis and correlation with serum CA125 in ovarian tumor patients. From The Danish "MALOVA" Ovarian Cancer Study. Gynecol Oncol 2007;104:508-15.

7. Bast RC, Klug TL, Stjohn E, et al. A radioimmunoassay using a monoclonal-antibody to monitor the course of epithelial ovarian-cancer. N Engl J Med 1983;309:883-7.

8. Hirsch M, Duffy JMN, Deguara CS, et al. Diagnostic accuracy of Cancer Antigen 125 (CA125) for endometriosis in symptomatic women: A multi-center study. Eur J Obstet Gynecol Reprod Biol 2017;210:102-7.

9. Levin G, Herzberg S, Dior UP, et al. The predictive role of CA-125 in the management of tubo-ovarian abscess. A retrospective study. Eur J Obstet Gynecol Reprod Biol 2019;238:20-4.

10. Pauler DK, Menon U, McIntosh M, et al. Factors Influencing Serum CA125II Levels in Healthy Postmenopausal Women. Cancer Epidemiol Biomarkers Prev 2001;10:489-93.

11. Akinwunmi BO, Babic A, Vitonis AF, et al. Chronic Medical Conditions and CA125 Levels among Women without Ovarian Cancer. Cancer Epidemiol Biomarkers Prev 2018;27:1483-90.

12. Moore RG, Miller MC, Steinhoff MM, et al. Serum HE4 levels are less frequently elevated than CA125 in women with benign gynecologic disorders. Am J Obstet Gynecol 2012;206:351 e1-8.

13. Moss EL, Hollingworth J, Reynolds TM. The role of CA125 in clinical practice. J Clin Pathol 2005;58:308-12.

14. Partridge E, Kreimer AR, Greenlee RT, et al. Results from four rounds of ovarian cancer screening in a randomized trial. Obstet Gynecol 2009;113:775-82.

15. Yin BW, Lloyd KO. Molecular cloning of the CA125 ovarian cancer antigen: identification as a new mucin, MUC16. J Biol Chem 2001;276:27371-5.

16. He SM, Xing F, Sui H, et al. Determination of CA125 levels in the serum, cervical and vaginal secretions, and endometrium in Chinese women with precancerous disease or endometrial cancer. Med Sci Monit 2011;17:CR618-625.

17. Matte I, Garde-Granger P, Bessette P, et al. Ascites from ovarian cancer patients stimulates MUC16 mucin expression and secretion in human peritoneal mesothelial cells through an Akt-dependent pathway. BMC Cancer 2019;19:406.

18. Kalantri Y, Naik G, Joshi SP, et al. Role of cancer antigen-125 from pleural \& ascitic fluid samples in non malignant conditions. Indian J Med Res 2007;125:25-30.

19. Halila H, Stenman UH, Seppala M. Ovarian-Cancer Antigen Ca-125 Levels in Pelvic Inflammatory Disease and Pregnancy. Cancer 1986;57:1327-9.

20. Maughan TS, Fish RG, Shelley M, et al. Antigen CA125 in tumor tissue and serum from patients with adenocarcinoma of the ovary. Gynecol Oncol 1988;30:342-6.

21. Hogdall EVS, Christensen L, Kjaer SK, et al. CA125 expression pattern, prognosis and correlation with serum CA125 in ovarian tumor patients - From The Danish "MALOVA" Ovarian Cancer Study. Gynecol Oncol 2007;104:508-15.

22. Potapenko IO, Haakensen VD, Luders T, et al. Glycan gene expression signatures in normal and malignant breast tissue; possible role in diagnosis and progression. Mol Oncol 2010;4:98-118.

23. Yanagi M, Aoyagi Y, Suda T, et al. $\mathrm{N}$-Acetylglucosaminyltransferase $\mathrm{V}$ as a possible aid for the evaluation of tumor invasiveness in patients with hepatocellular carcinoma. J Gastroenterol Hepatol 2001;16:1282-9.

24. Dube DH, Bertozzi CR. Glycans in cancer and inflammation. Potential for therapeutics and diagnostics. Nat Rev Drug Discov 2005;4:477-88.

25. Chen K, Gentry-Maharaj A, Burnell M, et al. Microarray Glycoprofiling of CA125 Improves Differential Diagnosis of Ovarian Cancer. J Proteome Res 2013;12:1408-18.

26. Akita K, Yoshida S, Ikehara Y, et al. Different Levels of Sialyl-Tn Antigen Expressed on MUC16 in Patients With Endometriosis and Ovarian Cancer. Int J Gynecol Cancer 2012;22:531-8.

27. Gidwani K, Huhtinen K, Kekki H, et al. A NanoparticleLectin Immunoassay Improves Discrimination of Serum CA125 from Malignant and Benign Sources. Clin Chem 2016;62:1390-400.

28. Chen S, LaRoche T, Hamelinck D, et al. Multiplexed analysis of glycan variation on native proteins captured by antibody microarrays. Nat Methods 2007;4:437-44.

29. Nishiyama T, Matsumoto Y, Watanabe H, et al. Detection of Tn antigen with Vicia villosa agglutinin in urinary bladder cancer: its relevance to the patient's clinical course. 
J Natl Cancer Inst 1987;78:1113-8.

30. Cramer DW, Bast RC, Jr., Berg CD, et al. Ovarian cancer biomarker performance in prostate, lung, colorectal, and ovarian cancer screening trial specimens. Cancer Prev Res (Phila) 2011;4:365-74.

31. Jacob F, Meier M, Caduff R, et al. No benefit from combining HE4 and CA125 as ovarian tumor markers in a clinical setting. Gynecol Oncol 2011;121:487-91.

32. Sandri MT, Bottari F, Franchi D, et al. Comparison of HE4, CA125 and ROMA algorithm in women with a pelvic mass: correlation with pathological outcome. Gynecol Oncol 2013;128:233-8.

33. Cornelissen LAM, Blanas A, Zaal A, et al. Tn Antigen Expression Contributes to an Immune Suppressive Microenvironment and Drives Tumor Growth in Colorectal Cancer. Front Oncol 2020;10:1622.

34. Ju T, Aryal RP, Kudelka MR, et al. The Cosmc connection to the Tn antigen in cancer. Cancer Biomark 2014;14:63-81.

35. Inoue $M$, Ton $S M$, Ogawa $H$, et al. Expression of Tn and sialyl-Tn antigens in tumor tissues of the ovary. Am J Clin Pathol 1991;96:711-6.

36. Jankovic MM, Milutinovic BS. Glycoforms of CA125 antigen as a possible cancer marker. Cancer Biomark 2008;4:35-42.

Cite this article as: Wang YS, Ren SF, Jiang W, Lu JQ, Zhang XY, Li XP, Cao R, Xu CJ. CA125-Tn ELISA assay improves specificity of pre-operative diagnosis of ovarian cancer among patients with elevated serum CA125 levels. Ann Transl Med 2021;9(9):788. doi: 10.21037/atm-20-8053
37. Salminen L, Nadeem N, Rolfsen AL, et al. Exploratory Analysis of CA125-MGL and-STn Glycoforms in the Differential Diagnostics of Pelvic Masses. J Appl Lab Med 2020;5:263-72.

38. Bouanene H, Miled A. Conflicting views on the molecular structure of the cancer antigen CA125/MUC16. Dis Markers 2010;28:385-94.

39. Jankovic MM, Tapuskovic BS. Molecular forms and microheterogeneity of the oligosaccharide chains of pregnancy-associated CA125 antigen. Hum Reprod 2005;20:2632-8.

40. Saldova R, Struwe WB, Wynne K, et al. Exploring the glycosylation of serum CA125. Int J Mol Sci 2013;14:15636-54.

41. Wong NK, Easton RL, Panico M, et al. Characterization of the oligosaccharides associated with the human ovarian tumor marker CA125. J Biol Chem 2003;278:28619-34.

42. Kuno A, Kato Y, Matsuda A, et al. Focused Differential Glycan Analysis with the Platform Antibody-assisted Lectin Profiling for Glycan-related Biomarker Verification. Mol Cell Proteomics 2009;8:99-108.

43. Thompson R, Creavin A, O'Connell M, et al. Optimization of the enzyme-linked lectin assay for enhanced glycoprotein and glycoconjugate analysis. Anal Biochem 2011;413:114-22. 


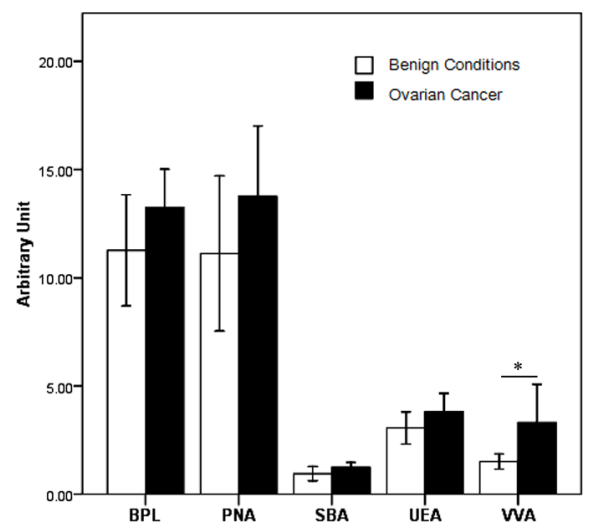

Figure S1 Antibody-lectin ELISA assay showed increased binding of VVA to CA125 in ovarian cancer patients $(\mathrm{n}=7)$. *, $\mathrm{P}<0.05$.

Table S1 Lectins and their corresponding inhibiting sugars

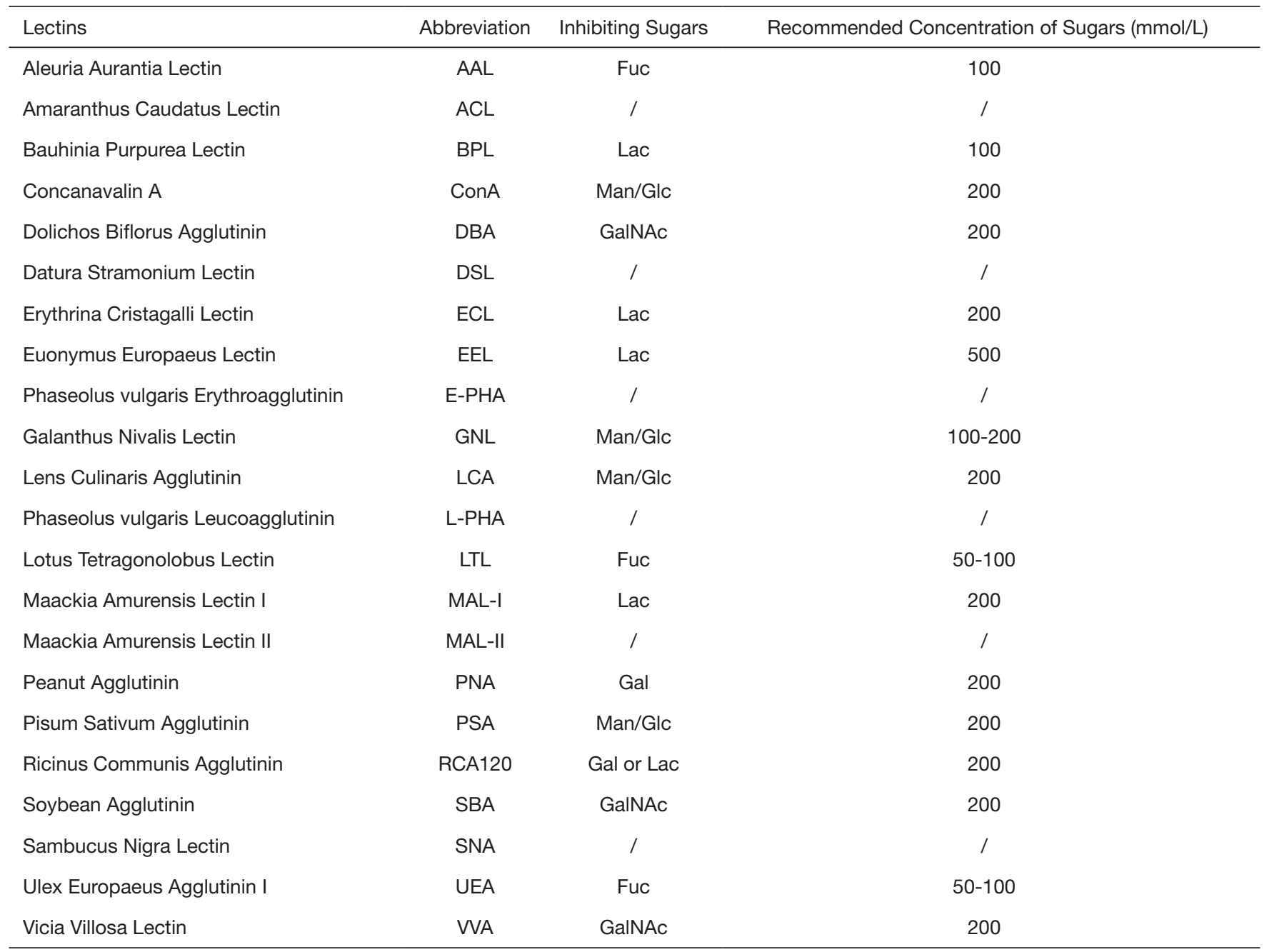

